\title{
Higher effective oronasal versus nasal continuous positive airway pressure in obstructive sleep apnea: Effect of mandibular stabilization
}

\author{
M Kaminska MD MSc ${ }^{1}$, A Montpetit DMD MSc${ }^{2}, \mathrm{~A}$ Mathieu $\mathrm{PhD}^{3}, \mathrm{~V}$ Jobin $\mathrm{MD}^{3}, \mathrm{~F}$ Morisson DMD PhD ${ }^{4}, \mathrm{P} \mathrm{Mayer} \mathrm{MD}^{3}$
}

M Kaminska, A Montpetit, A Mathieu, V Jobin, F Morisson, P Mayer. Higher effective oronasal versus nasal continuous positive airway pressure in obstructive sleep apnea: Effect of mandibular stabilization. Can Respir J 2014;21(4):234-238.

BACKGROUND: In some individuals with obstructive sleep apnea (OSA), oronasal continuous positive airway pressure (CPAP) leads to poorer OSA correction than nasal CPAP. The authors hypothesized that this results from posterior mandibular displacement caused by the oronasal mask.

OBJECTIVE: To test this hypothesis using a mandibular advancement device (MAD) for mandibular stabilization.

METHODS: Subjects whose OSA was not adequately corrected by oronasal CPAP at pressures for which nasal CPAP was effective were identified. These subjects underwent polysomnography (PSG) CPAP titration with each nasal and oronasal mask consecutively, with esophageal pressure and leak monitoring, to obtain the effective pressure (Peff) of CPAP for correcting obstructive events with each mask (maximum $20 \mathrm{cmH}_{2} \mathrm{O}$ ). PSG titration was repeated using a MAD in the neutral position. Cephalometry was performed.

RESULTS: Six subjects with mean $\left( \pm\right.$ SD) nasal Peff $10.4 \pm 3.0 \mathrm{cmH}_{2} \mathrm{O}$ were studied. Oronasal Peff was greater than nasal Peff in all subjects, with obstructive events persisting at $20 \mathrm{cmH}_{2} \mathrm{O}$ by oronasal mask in four cases. This was not due to excessive leak. With the MAD, oronasal Peff was reduced in three subjects, and Peff $<20 \mathrm{cmH}_{2} \mathrm{O}$ could be obtained in two of the four subjects with Peff $>20 \mathrm{cmH}_{2} \mathrm{O}$ by oronasal mask alone. Subjects' cephalometric variables were similar to published norms.

CONCLUSION: In subjects with OSA with higher oronasal than nasal Peff, this is partially explained by posterior mandibular displacement caused by the oronasal mask. Combination treatment with oronasal mask and MAD may be useful in some individuals if a nasal mask is not tolerated.

Key Words: Continuous positive airway pressure; CPAP mask; Mandibular advancement device; Obstructive sleep apnea

$\mathrm{O}$ bstructive sleep apnea (OSA) is a highly prevalent condition (1) that is associated with obesity and specific craniofacial features such as retrognathia, primarily in nonobese patients (2-4). OSA is best treated using continuous positive airway pressure (CPAP) (5). Mandibular advancement devices (MADs) are an alternative treatment in patients with mild-to-moderate OSA (6). A variety of interfaces are available for CPAP (7). Although nasal masks are most frequently used, oronasal masks, covering the nose and mouth, may be chosen due to patient preference, nasal obstruction or air leak through the mouth. In practice, nasal and oronasal masks are often used interchangeably, and are generally believed to be equally effective (7-9). There is, however, growing evidence suggesting that CPAP by oronasal mask is less effective at establishing airway patency in some individuals (10-13).

We hypothesized that, in individuals in whom oronasal CPAP is less effective than nasal CPAP at correcting upper airway obstruction, this results from posterior displacement of the mandible by the oronasal
La pression positive continue oronasale plus efficace que la pression positive continue nasale en apnée obstructive du sommeil : l'effet de la stabilisation mandibulaire

HISTORIQUE : Chez certaines personnes atteintes d'apnée obstructive du sommeil (AOS), la pression positive continue (PPC) oronasale corrige moins bien l'AOS que la PPC nasale. Les auteurs postulent que cette situation est causée par un déplacement de la mandibule postérieure attribuable au masque oronasal.

OBJECTIF : Vérifier cette hypothèse au moyen d'une orthèse d'avancée mandibulaire (OAM) pour stabiliser les mandibules.

MÉTHODOLOGIE : Les chercheurs ont déterminé les sujets dont l'AOS n'était pas bien corrigée par PPC oronasale à des pressions auxquelles la PPC nasale était efficace. Trois sujets se sont soumis au titrage de la PPC pendant une polysomnographie (PSG) par le masque nasal et le masque oronasal consécutivement, sous monitorage de la pression œsophagienne et des fuites, afin d'obtenir la pression efficace (Peff) de la PPC pour corriger les événements obstructifs à l'aide de chaque masque (maximum de $20 \mathrm{~cm} \mathrm{H}_{2} \mathrm{O}$ ). Le titrage de la PSG a été repris au moyen d'une OAM en position neutre. Une céphalométrie a été effectuée.

RÉSULTATS : Les chercheurs ont étudié six sujets présentant un Peff nasale moyenne ( \pm ÉT) de $10,4 \pm 3,0 \mathrm{~cm} \mathrm{H}_{2} \mathrm{O}$. La Peff oronasale était plus élevée que la Peff nasale chez tous les sujets, les événements obstructifs se produisait encore par le masque oronasal à $20 \mathrm{~cm} \mathrm{H}_{2} \mathrm{O}$ chez quatre patients. Cette situation n'était pas causée par une fuite excessive. Avec l'OAM, la Peff oronasale diminuait chez trois sujets, et une Peff inférieure à $20 \mathrm{~cm} \mathrm{H}_{2} \mathrm{O}$ a pu être observée chez deux des quatre sujets ayant une Peff supérieure à $20 \mathrm{~cm} \mathrm{H}_{2} \mathrm{O}$ par le seul masque oronasal. Les variables céphalométriques des sujets étaient similaires aux normes publiées.

CONCLUSION : Chez des sujets atteints d'AOS dont la Peff était plus élevée par voie oronasale que par voie nasale, la situation s'explique partiellement par le déplacement de la mandibule postérieure causé par le masque oronasal. Un traitement combiné par le masque oronasal et l'OAM peut être utile chez certaines personnes qui ne tolèrent pas le masque nasal.

mask, exacerbating upper airway obstruction. The primary objective of the present study was to determine whether mandibular stabilization in a neutral position using a MAD can reduce the oronasal CPAP level required for effective OSA correction in such individuals. The secondary objective was to evaluate whether any anatomical features are associated with poor response to oronasal CPAP by analyzing cephalometric characteristics.

\section{Subjects}

\section{METHODS}

Subjects were recruited from the sleep clinic of a tertiary care academic hospital. OSA was diagnosed based on clinical findings and sleep testing (American Academy of Sleep Medicine level 1 or 3 study). Based on clinical or polysomnography (PSG) records, individuals whose OSA was not adequately corrected by oronasal CPAP at pressures for which nasal CPAP was effective, or in whom high CPAP pressures were reached using an oronasal mask without achieving correction of

${ }^{1}$ Respiratory Epidemiology and Clinical Research Unit, McGill University, and Respiratory Division, McGill University Health Centre; ${ }^{2}$ Clinique d'Orthodontie, Université de Montréal; ${ }^{3}$ Sleep Laboratory, Centre Hospitalier Universitaire de Montreal - Hotel-Dieu, Montreal; ${ }^{4} 6900$ Bd

Cousineau, St-Hubert, Quebec

Correspondence: Dr Marta Kaminska, McGill University Health Centre, 687 Pine Avenue West, Room L4.08, Montreal, Quebec H3A 1A1.

Telephone 514-934-1934 ext 35650/36117, fax 514-843-1695, e-mail marta.kaminska@mcgill.ca 
TABLE 1

Subject characteristics and study results

\begin{tabular}{|c|c|c|c|c|c|c|c|c|c|c|}
\hline \multirow[b]{2}{*}{ Subject } & \multirow[b]{2}{*}{ Sex } & \multirow[b]{2}{*}{ Age, years } & \multirow{2}{*}{$\begin{array}{l}\text { Body mass } \\
\text { index, } \mathrm{kg} / \mathrm{m}^{2}\end{array}$} & \multirow[b]{2}{*}{ RDI } & \multirow[b]{2}{*}{ RDI supine } & \multicolumn{2}{|c|}{ Peff without MAD, $\mathrm{cmH}_{2} \mathrm{O}$} & \multicolumn{2}{|c|}{ Peff with MAD, $\mathrm{cmH}_{2} \mathrm{O}$} & \multirow{2}{*}{$\begin{array}{l}\text { Mask used in first } \\
\text { half of each night* }\end{array}$} \\
\hline & & & & & & Nasal & Oronasal & Nasal & Oronasal & \\
\hline 1 & Female & 64 & 20.9 & 27 & 41 & 10 & $>20$ & 11 & $>20$ & Nasal \\
\hline 2 & Male & 52 & 25.7 & 20 & 26 & 11 & $>20$ & 12 & $18^{\dagger}$ & Oronasal \\
\hline 3 & Male & 49 & 31.2 & 127 & 127 & 15 & $>20$ & 16 & $>20$ & Oronasal \\
\hline 4 & Male & 65 & 32.9 & 83 & 72 & 12 & $>20$ & 12 & $19^{\dagger}$ & Oronasal \\
\hline 5 & Male & 58 & 25.5 & 36 & 76 & 8 & 13 & 10 & 15 & Nasal \\
\hline 6 & Male & 33 & 32.7 & 48 & 68 & 10 & 18 & 9 & $10^{\dagger}$ & Nasal \\
\hline Mean \pm SD & & $53.5 \pm 11.9$ & $28.1 \pm 4.9$ & $56.8 \pm 40.1$ & $68.3 \pm 34.8$ & $10.4 \pm 3.0$ & $16.3 \pm 5.4$ & $11.1 \pm 2.6$ & $15.9 \pm 4.7$ & \\
\hline
\end{tabular}

*The maximal available continuous positive airway pressure was $20 \mathrm{cmH}_{2} \mathrm{O}$; ${ }^{\dagger}$ Clinically significant improvement in oronasal effective pressure (Peff) for correction of obstructive respiratory events in supine stage 2 sleep with versus without the mandibular advancement device (MAD). RDI Respiratory disturbance index

obstructive events, were identified. The present study was approved by the institutional ethics review board. Patients provided written informed consent.

\section{Procedures}

All subjects underwent overnight PSG twice. Each time, CPAP was titrated twice successively, once with a nasal mask and once with an oronasal mask. The order in which the masks were used was determined randomly for the first subject, alternating for subsequent subjects. The order of the first night was maintained for the second night. During the second PSG, CPAP titration was repeated using the MAD in the neutral position. All subjects also underwent cephalometry.

\section{PSG and CPAP titration}

Recording included standard electroencephalogram and electrooculogram leads, chin electromyography, electrocardiogram, snoring and body position (Sandman system, Covidien, USA). Oxygen saturation was measured using pulse oximetry (Oximax, Nellcor Puritan Bennett Ltd, USA). Respiratory efforts were measured via thoracic and abdominal piezoelectric belts. Respiratory flow was measured using a pneumotachograph (Hans Rudolph Inc, USA) directly connected to the mask. Pressure at the mask was measured via a pressure transducer (Validyne Engineering Corp, USA) connected through a catheter inserted into a tight opening in the mask shell. With the nasal mask, a thermistor was used to detect any airflow through the mouth. Intrathoracic pressure was recorded using an esophageal balloon (Cardinal Heath, USA) connected to a pressure transducer (Validyne, USA). Sleep scoring was performed according to Rechtschaffen and Kales (14).

For CPAP titration, the best-fitting size of nasal (Profile Lite, Philips-Respironics, USA) and oronasal (Disposable Non-vented Full Face Mask, ResMed, USA) masks were chosen for each subject by the same experienced respiratory therapist attending the PSG. Masks themselves were devoid of intentional leaks. The exhaust was distal to the pneumotachograph through a fenestrated connector piece. A BiPAP Synchrony connected to an Omnilab system (PhilipsRespironics, USA) was used for titration. Titration was performed only during supine stage 2 sleep, by increasing the pressure by $1 \mathrm{cmH}_{2} \mathrm{O}$ every $5 \mathrm{~min}$ until the effective pressure (Peff) was achieved for each type of mask or a maximal pressure of $20 \mathrm{cmH}_{2} \mathrm{O}$ was reached. Peff was defined by achievement of stable tidal breathing with absence of snoring and inspiratory esophageal pressure stability. Total air leak was continuously measured by the Omnilab system. Higher-than-expected leak led to mask readjustment before any further titration.

\section{MAD}

Subjects had a set of upper and lower dental impressions made in alginate (Plastalgin ortho, Septodont, USA) with a bite (Imprint Bite, 3M ESPE, USA) taken in maximum intercuspidation. A MAD (orthèse O.R.M, Laboratoires Narval, Res Med, USA) was fabricated in a neutral position (without any advancement of the mandible). The MAD was adjusted in the clinic by the same orthodontist for proper fit and comfort with and without the CPAP masks in place.

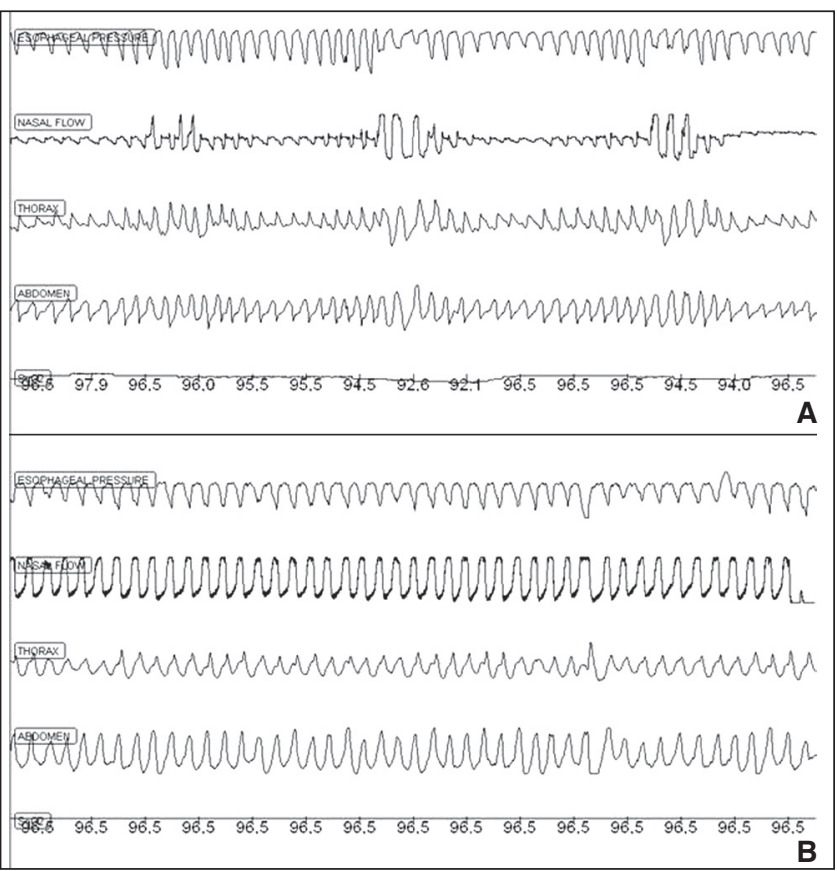

Figure 1) Example of polysomnographic recordings for subject 3 - oronasal versus nasal mask. Recordings with an oronasal mask at continuous positive airway pressure (CPAP) $20 \mathrm{cmH}_{2} \mathrm{O}$ (A), and with a nasal mask at CPAP $15 \mathrm{cmH}_{2} \mathrm{O}(\mathbf{B})$, both in supine stage 2 sleep. The epoch depicted is $180 \mathrm{~s}$. Inspiration on the nasal flow signal is an upward deflection

\section{Cephalometry}

Each subject underwent a lateral cephalometric radiograph (Orthophos CD orthopantomograph, Siemens, Canada) taken in natural head position to perform measurements using the landmarks shown in Appendix 1. The tracings and measurements (15) were performed manually from the radiograph by the same orthodontist on two different occasions for all subjects to ensure reproducibility of measurements (Appendix 2).

\section{RESULTS}

Six subjects were identified between July 2008 and February 2009. Subject characteristics are presented in Table 1. None of the subjects had undergone any oropharyngeal surgery.

Nasal Peff significantly correlated with the respiratory disturbance index $(\mathrm{r}=0.843 ; \mathrm{P}=0.04)$. Using the oronasal mask, Peff was not attained in four patients, with obstructive events persisting at the maximal CPAP of $20 \mathrm{cmH}_{2} \mathrm{O}$ (Figure 1). In the other two patients, oronasal Peff was higher than nasal Peff. Total air leak was similar with the two types of mask (Figure 2).

With mandibular stabilization, Peff by nasal mask remained within $1 \mathrm{cmH}_{2} \mathrm{O}$ of the nasal Peff without MAD for five of the six subjects, 


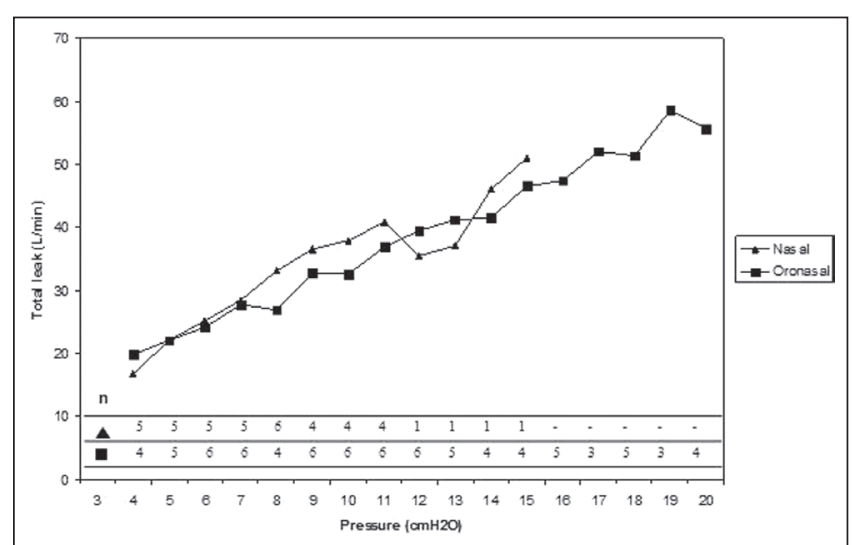

Figure 2) Total air leak during continuous positive airway pressure titration via nasal and oronasal mask (without mandibular advancement device). While leak was continuously available during polysomnography (PSG) titration on the Omnilab (Philips-Respironics, USA) system, it was not recorded as part of the PSG. Rather, it was documented intermittently as a comment; hence, it is not available for all subjects for all pressure levels

suggesting no direct effect of the MAD on airway obstruction. In the other subject (subject 5), nasal Peff increased by $2 \mathrm{cmH}_{2} \mathrm{O}$ (Table 1 ). Oronasal Peff decreased in three subjects, remained $>20 \mathrm{cmH}_{2} \mathrm{O}$ in two and increased in one (subject 5). Two individuals, who could not be treated by oronasal mask alone (Peff $>20 \mathrm{cmH}_{2} \mathrm{O}$ ), achieved oronasal Peff $19 \mathrm{cmH}_{2} \mathrm{O}$ and $18 \mathrm{cmH}_{2} \mathrm{O}$, respectively, with the MAD (Figure 3).

Cephalometric measurements were compared with published norms $(16,17)$ by calculating $\mathrm{Z}$ scores. The group mean $\mathrm{Z}$ score for each measurement was $>-1.65$, suggesting no significant differences compared with the general population.

\section{DISCUSSION}

We identified and studied individuals with OSA whose Peff by oronasal mask was considerably higher compared with nasal Peff. In four patients, airway patency could not be established by oronasal mask even with CPAP $20 \mathrm{cmH}_{2} \mathrm{O}$, but CPAP by nasal mask resulted in stable breathing at $\leq 15 \mathrm{cmH}_{2} \mathrm{O}$. We used esophageal manometry to confirm the obstructive nature of the persistent respiratory events. Excessive air leak was not responsible for the difference between masks. Mandibular stabilization resulted in partial reduction of the higher oronasal Peff.

While oronasal masks were previously found to be effective for OSA treatment $(8,9,11,18)$, several reports suggest they may not be equivalent, at least in some patients, to nasal masks. In one study, oronasal Peff was at least $2 \mathrm{cmH}_{2} \mathrm{O}$ greater than nasal Peff in $46 \%$ of patients. In other studies, patient satisfaction and average nightly compliance were lower (18), and sleep was slightly more perturbed (8) with oronasal compared with nasal masks. It has been suggested that the higher Peff by oronasal mask is primarily due to excessive air leak (12). Our results suggest otherwise: any excessive leak led to immediate mask readjustment and leak was equivalent for both types of masks (Figure 2). Interestingly, in a physiological study, Smith et al (19) were unable to obtain airway patency by oronasal mask in their group of subjects. The discrepancy between the results from the study by Smith et al (19) and the prevalent use of oronasal CPAP has not been explained. A recent case report (10) described a patient in whom nasal CPAP was effective at a relatively low pressure whereas oronasal CPAP resulted in persistent airway obstruction with elevated pressures; endoscopy confirmed oropharyngeal airway obstruction.

Oronasal masks may cause or exacerbate upper airway obstruction directly by displacing the mandible posteriorly. We used a MAD in the neutral position in conjunction with oronasal CPAP to verify this hypothesis. MADs are a treatment option for mild-to-moderate OSA,

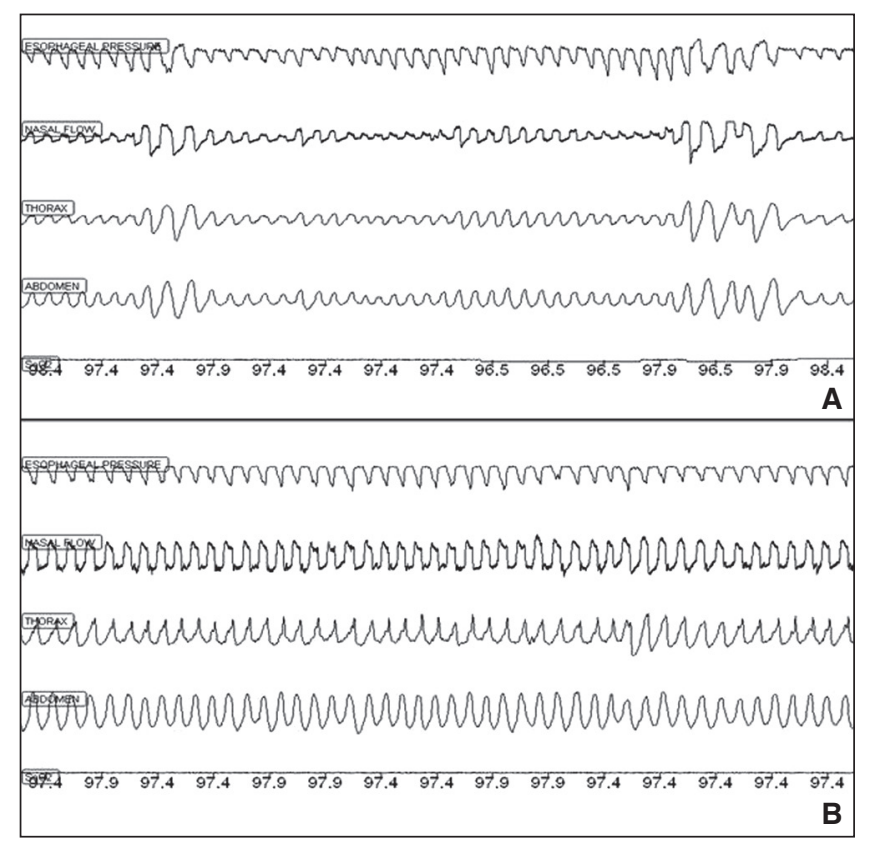

Figure 3) Example of polysomnographic recordings for subject 2 - oronasal mask with and without mandibular retention. Recordings with an oronasal mask alone at continuous positive airway pressure (CPAP) $20 \mathrm{cmH}_{2} \mathrm{O}$ (A), and with an oronasal mask AND mandibular advancement device at CPAP $18 \mathrm{cmH}_{2} \mathrm{O}$ (B), both in supine stage 2 sleep. The epoch depicted is $180 \mathrm{~s}$. Inspiration on the nasal flow signal is an upward deflection

particularly in nonobese patients with positional OSA (6). A response (significant partial or complete OSA correction) has been associated with an increase in the size of the pharyngeal lumen (20). We expected the MAD in neutral position to lower oronasal Peff to close to nasal Peff by preventing any posterior manibular displacement caused by the oronasal mask. Nasal Peff showed no or minimal change, confirming that there was no significant direct effect of the MAD on upper airway obstruction. With the oronasal mask, the MAD appeared to show partial benefit in three of the six patients. Hence, it appears that mandibular displacement accounted in part for the unfavourable effect of the oronasal mask, and that the mechanisms underlying poor oronasal mask effectiveness may differ among individuals. This may be related to different sites of obstruction. In the single case described by Schorr et al (10), endoscopy demonstrated posterior displacement of the base of the tongue with the oronasal mask. However, the level of obstruction may differ among individuals. Also, the MAD may not achieve the same effect in all cases. The literature suggests that patients with oropharyngeal collapse at baseline (21) or a smaller oropharynx (22) are more likely to respond to a MAD. However, a magnetic resonance imaging study showed that response to the MAD was primarily explained by expansion of the velopharyngeal volume in its lateral dimension (20). It should also be noted that the MAD itself may create a change in the position of the mandible by opening the occlusion, as well as crowding in the mouth with posterior displacement of the tongue. Both of these factors may exacerbate airway obstruction. These effects may explain the small increase in both nasal and oronasal Peff in one of our cases. However, because nasal Peff did not change significantly with the MAD for the remaining subjects, this effect is unlikely to be relevant in most cases.

With an oronasal mask, patients may mouth breathe and mouth opening may be responsible for mandibular position change, which can in turn affect upper airway patency because the position of the mandible (23) and tongue (24) are significant elements in OSA pathogenesis. Additionally, CPAP, when applied at the nose and mouth simultaneously, may fail to achieve a sufficient airway transmural pressure 
difference to establish airway patency (19). Mouth breathing can also increase upper airway surface tension, in turn worsening OSA (25). The MAD may then work by promoting mouth closure and tongue apposition to the palate. We did not ascertain mouth opening with the oronasal mask in our study. However, Sanders et al (9) showed that even with a mouthpiece in place to maintain the mouth open, oronasal CPAP remained effective at a level comparable with the nasal mask in their group of subjects, suggesting that mouth opening does not explain oronasal CPAP ineffectiveness, although the effect, once again, may vary among individuals and the mouthpiece itself may alter the physiology.

Concomitant use of the MAD in neutral position with CPAP was well tolerated in our subjects, although more long-term data will be needed to confirm our single-night findings. Nevertheless, concomitant use of CPAP with a MAD is feasible and could be a treatment option in patients who do not tolerate nasal CPAP but have very high or unattainable oronasal Peff.

While not assessed in the present study, the MAD with mandibular advancement may further reduce oronasal Peff, and likely also nasal Peff. This may be useful for treatment of severe OSA. It is conceivable that both a MAD and CPAP, used concomitantly, could be titrated for optimal OSA correction while minimizing the discomfort and adverse effects of excessive mandibular advancement and high pressure, respectively. This may lead to improved overall tolerance and, hence, adherence to OSA treatment.

A limitation of our study was that two titrations (one with each mask) were performed consecutively during a single night, once without and once with the MAD. To avoid any potential effect of differences in OSA from early to late night, we have alternated the type of mask used first (Table 1), and standardized our analyses to supine stage 2 sleep only. Additionally, while the technologist was aware of the results of the first titration while performing the second titration of each night, bias

APPENDIX 1

Lateral cephalometric landmarks

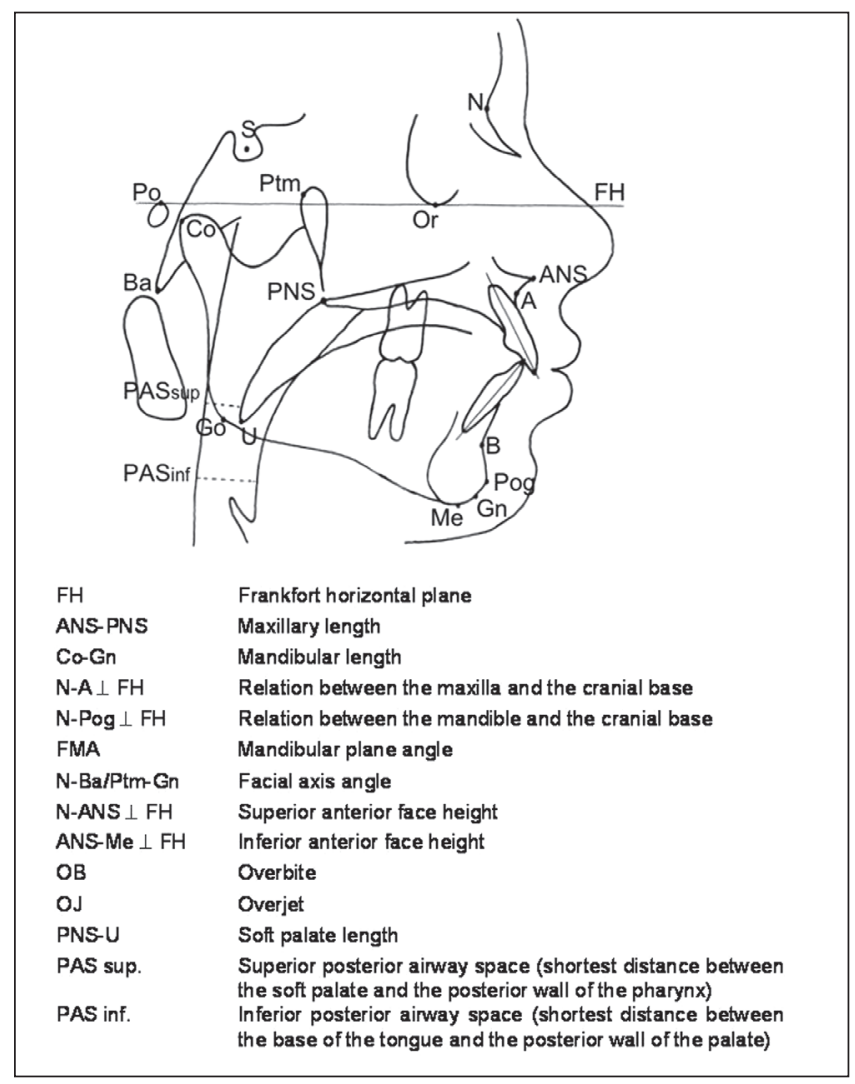

was minimized by using esophageal pressure monitoring to reduce the risk of overtitration.

We did not find any cephalometric variables in our subjects that could predict ineffectiveness of oronasal CPAP or its improvement with the MAD. Changes in airway dimensions may occur in the supine position (26), which we did not assess. Cephalometric data should be interpreted with caution given our limited sample size.

\section{SUMMARY}

Although the prevalence of the difference in nasal versus oronasal CPAP effectiveness and impact on CPAP adherence are unknown, it is important to be aware of this potential source of CPAP failure. Given the increasingly recognized adverse consequences of OSA, optimizing treatment effectiveness and adherence is an important goal for each patient. Our data suggest that it may be feasible to combine therapy using a MAD with oronasal CPAP in individuals intolerant to CPAP by nasal mask.

ACKNOWLEDGEMENTS: The authors acknowledge Dr Francois Bellemare for his help in setting up the study protocol. They extend their thanks to Magalie Valières who performed the titration studies, and to Anne-Marie Laurin, Chief Technician of the Sleep Laboratory of the Centre-Hospitalier Universitaire de Montreal.

FUNDING: This study was funded by the Foundation of the Centre Hospitalier Universitaire de Montreal.

DISCLOSURES: The authors have no financial disclosures or conflicts of interest to declare.

\section{APPENDIX 2}

Cephalometric variables (see Appendix 1 for landmarks)

\begin{tabular}{|c|c|c|}
\hline $\mathrm{FH}$ & $\begin{array}{l}\text { Frankfort horizontal } \\
\text { plane }\end{array}$ & $\begin{array}{l}\text { Plane built from the line joining porion } \\
\text { (Po) and orbital (Or) points }\end{array}$ \\
\hline Co-A & Maxillary length & $\begin{array}{l}\text { Distance in mm between condylion } \\
\text { (Co) and subspinal (A) points }\end{array}$ \\
\hline ANS-PNS & Maxillary length & $\begin{array}{l}\text { Distance in mm between the anterior } \\
\text { nasal spine (ANS) and the posterior } \\
\text { nasal spine (PNS) points }\end{array}$ \\
\hline Co-Gn & Mandibular length & $\begin{array}{l}\text { Distance in mm between condylion } \\
(\mathrm{Co}) \text { and gnation }(\mathrm{Gn}) \text { points. }\end{array}$ \\
\hline SNA & $\begin{array}{l}\text { Antero-posterior } \\
\text { position of the } \\
\text { maxilla }\end{array}$ & $\begin{array}{l}\text { Angle formed by nasion }(\mathrm{N}) \text {, sella }(\mathrm{S}) \\
\text { and subspinal }(\mathrm{A}) \text { points }\end{array}$ \\
\hline SNB & $\begin{array}{l}\text { Antero-posterior } \\
\text { position of the } \\
\text { mandible }\end{array}$ & $\begin{array}{l}\text { Angle formed by nasion }(\mathrm{N}) \text {, sella }(\mathrm{S}) \\
\text { and supramental }(\mathrm{B}) \text { points }\end{array}$ \\
\hline ANB & $\begin{array}{l}\text { Antero-posterior } \\
\text { relation between the } \\
\text { maxilla and the } \\
\text { mandible }\end{array}$ & $\begin{array}{l}\text { Angle formed by subspinal }(A), \\
\text { nasion }(N) \text { and supramental }(B) \\
\text { points }\end{array}$ \\
\hline $\mathrm{N}-\mathrm{A} \perp \mathrm{FH}$ & $\begin{array}{l}\text { Antero-posterior } \\
\text { position of the } \\
\text { maxilla }\end{array}$ & $\begin{array}{l}\text { Distance in } \mathrm{mm} \text { between a line } \\
\text { perpendicular to } \mathrm{FH} \text { plane at nasion } \\
\text { (N) point and subspinal }(\mathrm{A}) \text { point. }\end{array}$ \\
\hline N-Pog $\perp$ FH & $\begin{array}{l}\text { Antero-posterior } \\
\text { relation of the } \\
\text { mandible }\end{array}$ & $\begin{array}{l}\text { Distance in } \mathrm{mm} \text { between a line } \\
\text { perpendicular to } \mathrm{FH} \text { plane at nasion } \\
\text { (N) point and pogonion (Pog) point }\end{array}$ \\
\hline \multirow[t]{2}{*}{ FMA } & $\begin{array}{l}\text { Mandibular plane } \\
\text { angle }\end{array}$ & $\begin{array}{l}\text { Angle formed between the } \\
\text { mandibular plane and } \mathrm{FH} \text { plane }\end{array}$ \\
\hline & & Mandibular plane: Line joining gnation \\
\hline
\end{tabular}

$(\mathrm{Gn})$ and menton $(\mathrm{Me})$ points

Continued on next page 


\section{APPENDIX 2 - CONTINUED Cephalometric variables} $\mathrm{N}-\mathrm{Ba} / \mathrm{Ptm}-\mathrm{Gn}$ Facial axis angle

$\mathrm{N}$-ANS $\perp$ FH $\quad$ Upper anterior face height

ANS-Me $\perp$ FH Lower anterior face height

I/SN

Upper incisor angulation

OB

Overbite

OJ

Overjet

PNS-U Soft palate length

Posterior airway
space at oropharynx
level

PAS inf.

Posterior airway

space at laryngopharynx level wall of the pharynx

\section{REFERENCES}

1. Young T, Palta M, Dempsey J, Skatrud J, Weber S, Badr S.

The occurrence of sleep-disordered breathing among middle-aged adults. N Engl J Med 1993;328:1230-5.

2. Chi L, Comyn FL, Mitra N, et al. Identification of craniofacial risk factors for obstructive sleep apnoea using three-dimensional MRI. Eur Respir J 2011;38:348-58

3. Mayer P, Pepin JL, Bettega G, et al. Relationship between body mass index, age and upper airway measurements in snorers and sleep apnoea patients. Eur Respir J 1996;9:1801-9.

4. Sakakibara H, Tong M, Matsushita K, Hirata M, Konishi Y, Suetsugu S. Cephalometric abnormalities in non-obese and obese patients with obstructive sleep apnoea. Eur Respir J 1999;13:403-10.

5. Kushida CA, Littner MR, Hirshkowitz M, et al. Practice parameters for the use of continuous and bilevel positive airway pressure devices to treat adult patients with sleep-related breathing disorders. Sleep 2006;29:375-80.

6. Kushida CA, Morgenthaler TI, Littner MR, et al. Practice parameters for the treatment of snoring and obstructive sleep apnea with oral appliances: An update for 2005. Sleep 2006;29:240-3.

7. Chai CL, Pathinathan A, Smith B. Continuous positive airway pressure delivery interfaces for obstructive sleep apnoea. Cochrane Database Syst Rev 2006:CD005308.
8. Prosise GL, Berry RB. Oral-nasal continuous positive airway pressure as a treatment for obstructive sleep apnea. Chest 1994;106:180-6.

9. Sanders MH, Kern NB, Stiller RA, Strollo PJ Jr, Martin TJ, Atwood CW Jr. CPAP therapy via oronasal mask for obstructive sleep apnea. Chest 1994;106:774-9.

10. Schorr F, Genta PR, Gregorio MG, Danzi-Soares NJ, Lorenzi-Filho G. Continuous positive airway pressure delivered by oronasal mask may not be effective for obstructive sleep apnoea. Eur Respir J 2012;40:503-5.

11. Teo M, Amis T, Lee S, Falland K, Lambert S, Wheatley J. Equivalence of nasal and oronasal masks during initial CPAP titration for obstructive sleep apnea syndrome. Sleep 2011;34:951-5.

12. Bakker JP, Neill AM, Campbell AJ. Nasal versus oronasal continuous positive airway pressure masks for obstructive sleep apnea: A pilot investigation of pressure requirement, residual disease, and leak. Sleep Breath 2012;16:709-16.

13. Ebben MR, Oyegbile T, Pollak CP. The efficacy of three different mask styles on a PAP titration night. Sleep Med 2012;13:645-9.

14. Rechtschaffen A, Kales A, eds. Brain Research Institute, University of California. A manual of standardized terminology, techniques and scoring system of sleep stages in human subjects. Los Angeles, 1968.

15. McNamara JA Jr. A method of cephalometric evaluation. Am J Orthod 1984;86:449-69.

16. Mostafiz W, Dalci O, Sutherland K, et al. Influence of oral and craniofacial dimensions on mandibular advancement splint treatment outcome in patients with obstructive sleep apnea. Chest 2011;139:1331-9.

17. Ng AT, Darendeliler MA, Petocz P, Cistulli PA. Cephalometry and prediction of oral appliance treatment outcome. Sleep Breath 2012;16:47-58.

18. Mortimore IL, Whittle AT, Douglas NJ. Comparison of nose and face mask CPAP therapy for sleep apnoea. Thorax 1998;53:290-2.

19. Smith PL, Wise RA, Gold AR, Schwartz AR, Permutt S. Upper airway pressure-flow relationships in obstructive sleep apnea. J Appl Physiol 1988;64:789-95.

20. Chan AS, Sutherland K, Schwab RJ, et al. The effect of mandibular advancement on upper airway structure in obstructive sleep apnoea. Thorax 2010;65:726-32.

21. Ng AT, Qian J, Cistulli PA. Oropharyngeal collapse predicts treatment response with oral appliance therapy in obstructive sleep apnea. Sleep 2006;29:666-71.

22. Liu Y, Lowe AA, Fleetham JA, Park YC. Cephalometric and physiologic predictors of the efficacy of an adjustable oral appliance for treating obstructive sleep apnea. Am J Orthod Dentofacial Orthop 2001;120:639-47.

23. Meurice JC, Marc I, Carrier G, Series F. Effects of mouth opening on upper airway collapsibility in normal sleeping subjects. Am J Respir Crit Care Med 1996;153:255-9.

24. Cartwright RD, Samelson CF. The effects of a nonsurgical treatment for obstructive sleep apnea. The tongue-retaining device. JAMA 1982;248:705-9.

25. Verma M, Seto-Poon M, Wheatley JR, Amis TC, Kirkness JP. Influence of breathing route on upper airway lining liquid surface tension in humans. J Physiol 2006;574:859-66.

26. Pae EK, Lowe AA, Sasaki K, Price C, Tsuchiya M, Fleetham JA. A cephalometric and electromyographic study of upper airway structures in the upright and supine positions. Am J Orthod Dentofacial Orthop 1994;106:52-9. 


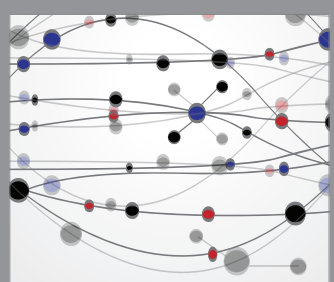

The Scientific World Journal
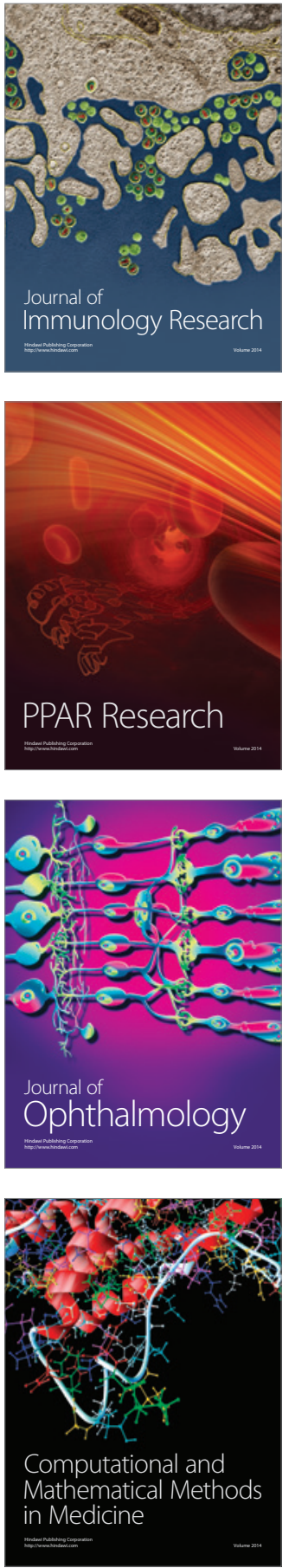

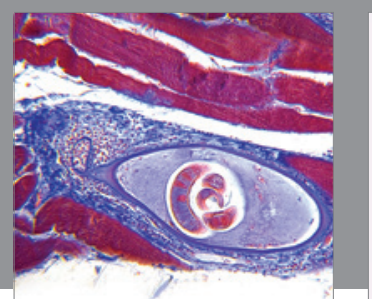

Gastroenterology Research and Practice

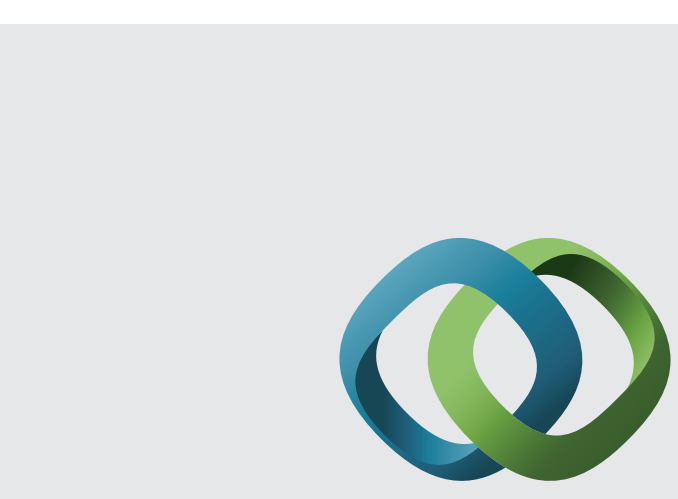

\section{Hindawi}

Submit your manuscripts at

http://www.hindawi.com
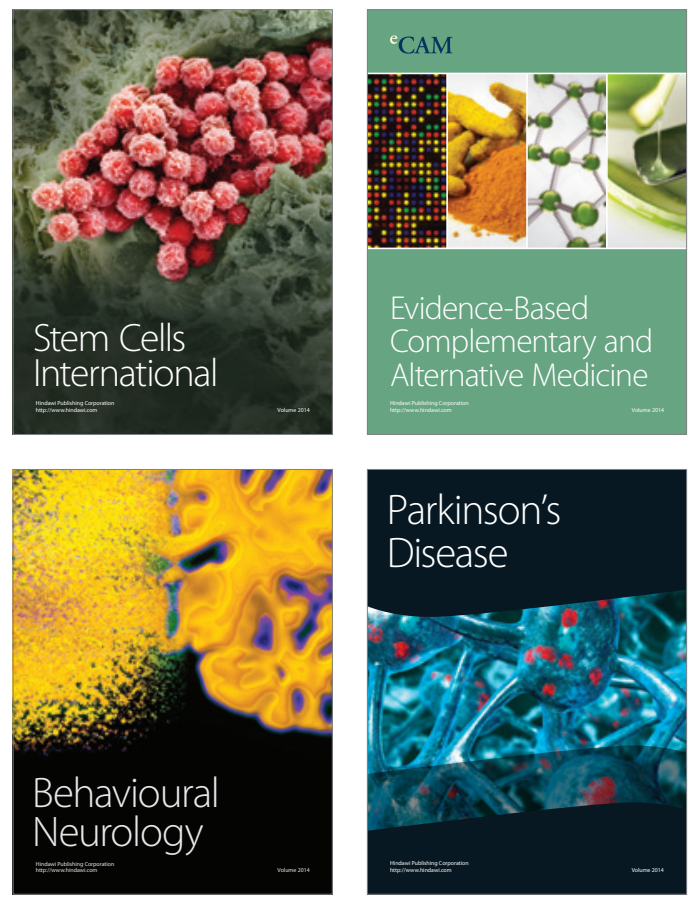
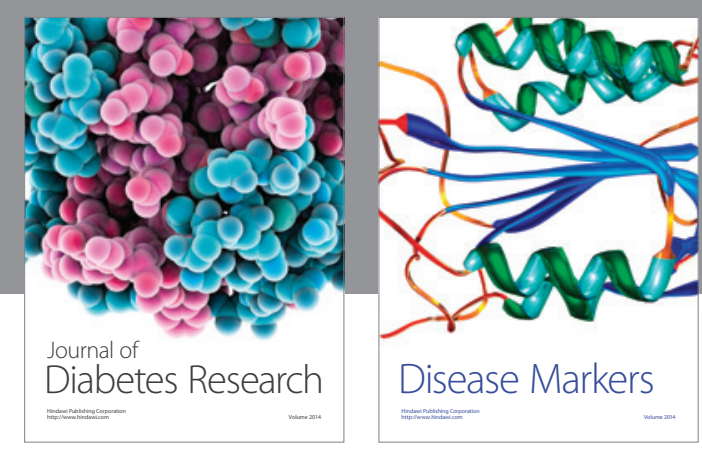

Disease Markers
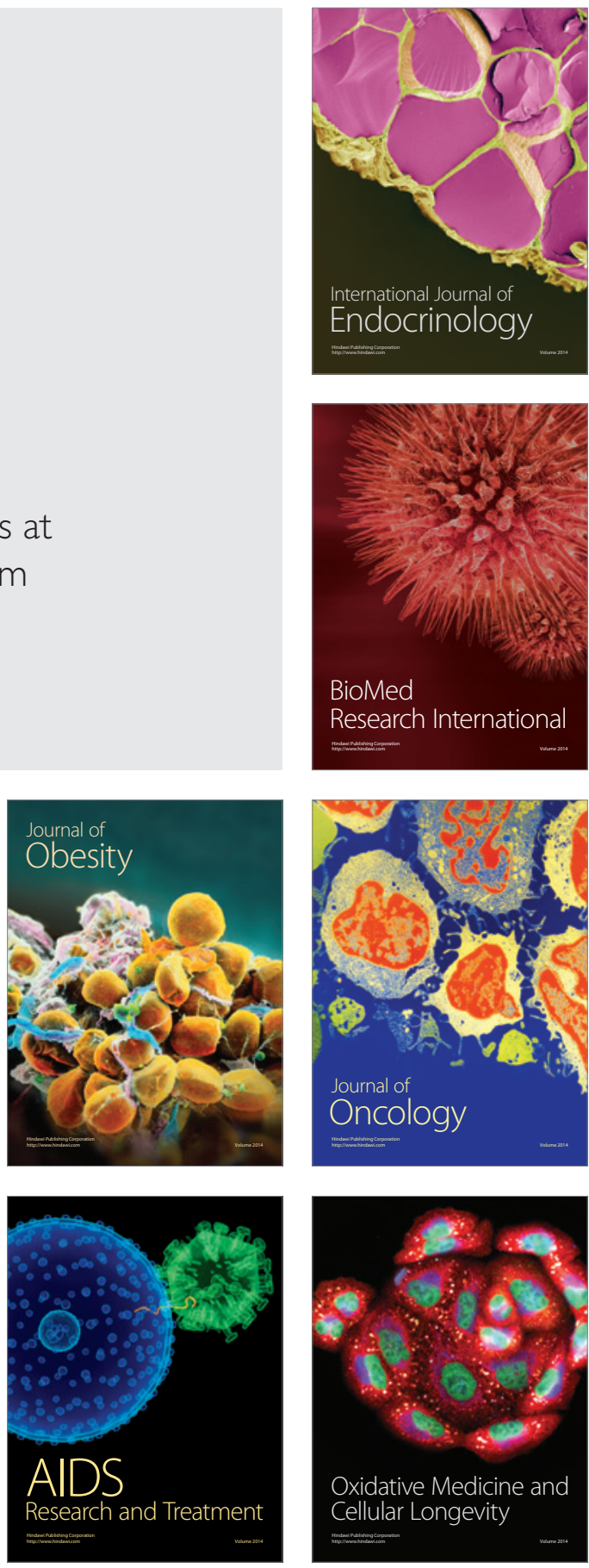